\title{
Secundum type atrial septal defect with prolonged PR interval and autosomal dominant mode of inheritance
}

\author{
Per G. Björnstad \\ From the Department of Paediatric Cardiology, Paediatric Clinic, Rikshospitalet, University of Oslo, Oslo, \\ Norway
}

This report describes a family where secundum type atrial septal defect with prolonged atrioventricular conduction time occurred certainly in 6, and probably in at least I more, members of the family in 3 or 4 generations. No skeletal anomalies were found. Because of a certain type of kinship in two affected branches, and an almost 50-50 distribution case among sibs and the two sexes, an autosomal dominant mode of inheritance with complete penetrance is probable.

The affinity of some chromosomal anomalies for certain types of congenital heart disease is well known, e.g. atrioventricular defects in Down's syndrome and coarctation of the aorta in Turner's syndrome. Many reports on several types of congenital heart disease in close or more distant family relationships have aroused suspicion that genetic factors may be important also in other patients. Reports on the increased incidence of congenital heart diseases in the families of patients with some kind of congenital heart disease have stressed the genetic component (Emanuel, 1970). A report on familial atrial septal defect postulated multifactorial mode of inheritance as the most probable explanation (Nora, McNamara, and Fraser, 1967).

Some cases of congenital heart disease, however, do not seem to fit into a pattern of multifactorial inheritance, e.g. the syndrome reported by Holt and Oram (1960). There are also reported cases of inherited simple atrial septal defect and the author has been able to find published reports of 15 families where isolated septal defect occurred in more than 2 cases in at least 2 generations (Amarashingham and Fleming, 1967; Bizarro et al., 1970; Campbell, 1949; Campbell and Polani, I96r; Carleton, Abelmann, and Hancock, 1958; Davidsen, 1958; Ehlers and Engle, 1966; Howitt, 1961; Kahler et al., 1966; Nora et al., 1967; Weil and Allenstein, 196I; Zetterqvist et al., 1971; Zuckerman et al., 1962). But really good evidence for a dominant mode of inheritance is found only in 8 families. In 6 of these families there was prolonga-

Received 13 February 1974 . tion of the PR interval as well (Amarashingham and Fleming, 1967; Bizarro et al., 1970; Howitt, 196I; Kahler et al., 1966; Weil and Allenstein, 1961).

The purpose of this article is to describe a family which because of a certain type of kinship gives further evidence for the autosomal dominant mode of inheritance.

\section{Case V.2}

\section{Family report (Fig. I)}

The proband, who is her parent's second child, was born at term after a normal pregnancy, but was slightly cyanotic for some time after birth and also later when crying. She did not gain weight properly and was admitted to the local children's hospital, and from there she was transferred to us with a suspicion of congenital heart disease. She was small for her age and underweight, her length corresponding to the Ioth percentile for age, and her weight $800 \mathrm{~g}$ less than the 2.5 percentile for her length. There was a systolic murmur of grade $2 / 6$ and a pronounced diastolic murmur of grade 4/6 (Fig. 2). Electrocardiogram and catheterization data are listed in the Table. She is now awaiting operation.

\section{Case IV.I}

Brother of the proband's father. Gestation and delivery were normal. He is said to have started walking late, otherwise he had completely normal development. Physical activity was normal and he was able to run faster than most of his peers. No cyanosis was noted. At almost 7 years of age he had an episode of syncope of approximately I minute's duration: while standing on the ground he fell, was very weak without convulsions, had stertorous respirations, and became acrocyanotic. 


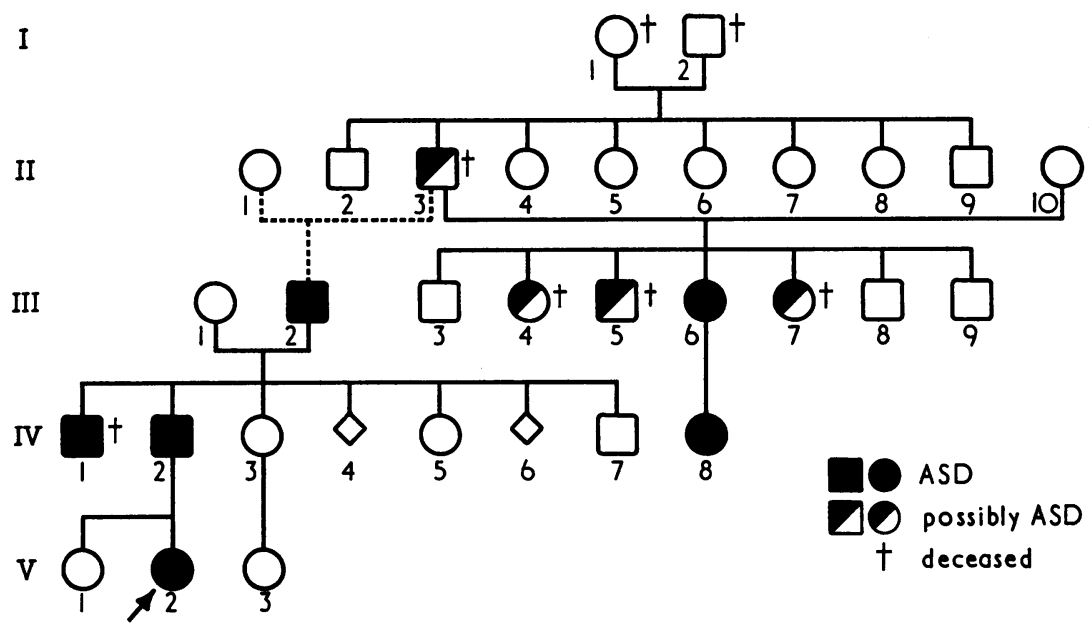

FIG. I Pedigree of proband (V.2, arrow). Black symbols indicate atrial septal defect of secundum type with prolongation of the atrioventricular conduction time, one of them (IV.I) diagnosed clinically only, the other ones by catheter study. Two with a large septal defect (III.2 and III.6) have been operated upon. Black and white symbols indicate likely or possible atrial septal defect, but no further information is available because they are dead. Atrial fibrillation occurred in cases III.2, III.6, II.2, II.3, II.4, II.6, and II.7. $\diamond=$ spontaneous abortions.

Shortly afterwards he was all right. Some months later he fainted in his bed and had very shallow breathing and pronounced cyanosis for about half an hour. He was drowsy afterwards and slept for several hours. He was examined in the local hospital where episodes of irregular pulse were found. After a period of regular pulse an interval of 3 to 4 seconds occurred with no pulse or heart sounds, followed by a pronounced irregular pulse. Shortly afterwards he was examined by an experienced cardiologist in our hospital by electrocardiogram and $x$-ray, and an atrial septal defect of secundum type was diagnosed. While waiting for a cardiac catheter study he died at home at about $7 \frac{1}{2}$ years of age. The last two days before death he had increased nervousness, dyspnoea, cyanosis, and intermittent praecordial pain. No necropsy was performed.

\section{Case IV.2}

Father of the proband. He has always been well and there are no reports of special events during gestation, delivery, or early childhood. At 7 years of age he was examined at the local hospital where atrial septal defect was suspected from the systolic and diastolic murmurs and the electrocardiographic abnormalities. He has led a normal life, and did his military service as a sergeant in the infantry. He was further examined in the medical department and the findings are summarized in the Table. The patient had a remarkably long PR interval which increased to 0.54 in the course of 15 years (Fig. 3). He is awaiting operation.

\section{Case III.2}

The proband's grandfather. He has been known to have heart disease since a routine examination at the age of 14 . He has always been short of breath and complained of palpitations. During his military service he was examined in our hospital where atrial flutter was found and mitral stenosis and regurgitation were suspected. After treatment with quinidine and DC shock he had a brief attack of sinus rhythm with a prolonged PR interval. He was recently operated upon in our hospital, at 46 years of age, and found to have a large secundum type atrial septal defect of more than 3 by $3 \mathrm{~cm}$, with a central bridge. It was closed with a 'dacron' patch. The postoperative course has been good so far.

\section{Case III.6}

The half-sister of the proband's grandfather. She had frequent episodes of bronchitis from the age of 3 , tired easily from the age of 5 , and at 7 years of age a clinical diagnosis of atrial septal defect was made. Six years later she became cyanotic under stress. When she was I7 years old she was operated on and a huge septal defect of secundum type going from the upper to the lower caval vein was sutured. The day after operation she developed atrial fibrillo-flutter which has persisted. Except for her atrial flutter and occasional 'heart feelings' she had been well. Her only pregnancy was uneventful, except for slight hypertension and moderate oedema for the last month. 


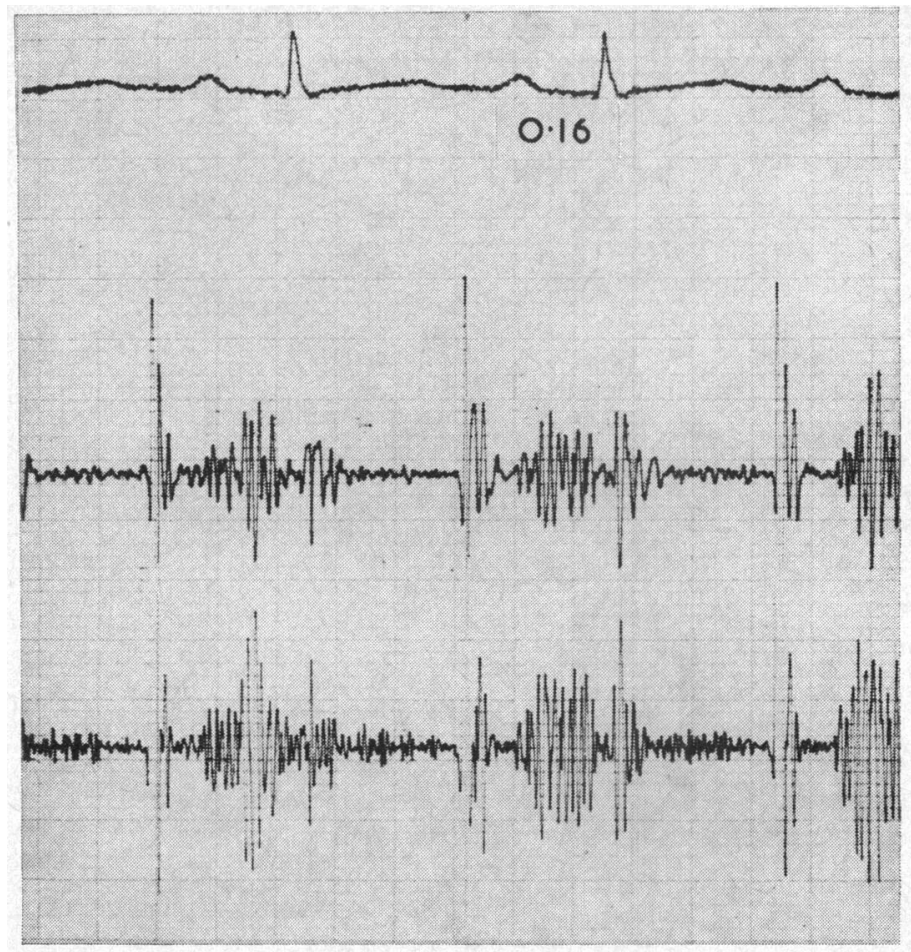

FIG. 2 Phonocardiogram of proband (V.2) recorded from the fourth left intercostal space at medium and high frequencies with a paper speed of $50 \mathrm{~mm} / \mathrm{sec}$. A very pronounced diastolic murmur with fixed splitting of the second heart sound is demonstrated. The PR interval of $0.16 \mathrm{sec}$ is at the upper normal limit for age.

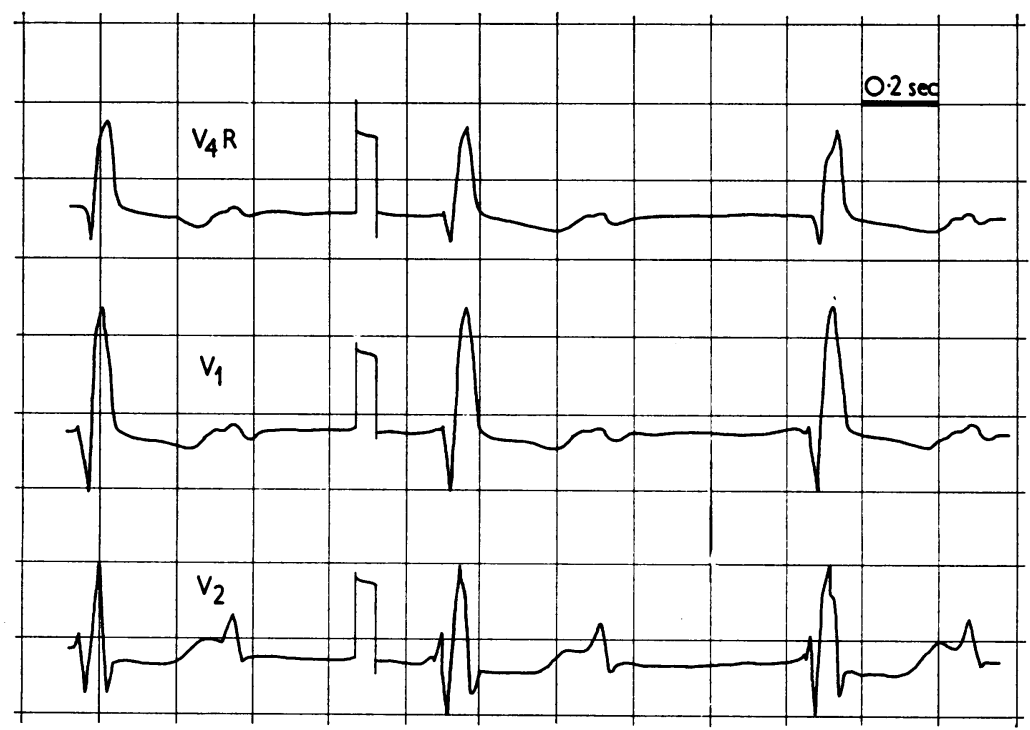

FIG. 3 Electrocardiogram from the proband's father (IV.2) 1972 showing a first-degree atrioventricular block with an atrioventricular conduction time of $0.54 \mathrm{sec}$, an incomplete right bundlebranch block, and a right ventricular hypertrophy. Paper speed $50 \mathrm{~mm} / \mathrm{sec}$. 
TABLE Electrocardiographic and catheter data from patients in the family

\begin{tabular}{|c|c|c|c|c|c|c|}
\hline Patient & Sex & $\begin{array}{l}\text { Year } \\
\text { of } \\
\text { birth }\end{array}$ & $\begin{array}{l}\text { Year } \\
\text { of } \\
\text { study }\end{array}$ & $\begin{array}{l}P R \text { interval (sec) or } \\
\text { type of rhythm } \\
\text { disturbances }\end{array}$ & $\begin{array}{l}\text { Upper } \\
\text { normal } \\
\text { limit } \\
\text { for age }(\mathrm{sec})\end{array}$ & $\begin{array}{l}\text { Right } \\
\text { ventricular } \\
\text { hypertrophy }\end{array}$ \\
\hline II.3 & $\mathbf{M}$ & 1903 & 1958 & Atrial fibrillation & 一 & $\begin{array}{l}\text { Complete } \\
\text { right bundle- } \\
\text { branch block }\end{array}$ \\
\hline III.2 & $\mathbf{M}$ & 1926 & $\begin{array}{l}1954 \\
1954 \\
1972\end{array}$ & $\begin{array}{l}\text { Atrial flutter } \\
0 \cdot 32 \\
\text { Atrial tachycardia, total } \\
\text { AV block }\end{array}$ & 0.20 & $\begin{array}{l}? \\
+ \\
+\end{array}$ \\
\hline III.6 & $\mathbf{F}$ & I944 & $\begin{array}{l}1951 \\
1958 \\
1961\end{array}$ & $\begin{array}{l}0.28-0.30 \\
0.36 \\
\text { Atrial flutter }\end{array}$ & $\begin{array}{l}0.18 \\
0.20\end{array}$ & $\begin{array}{l}+ \\
+ \\
+\end{array}$ \\
\hline $\begin{array}{l}\text { IV.I } \\
\text { IV.2 }\end{array}$ & $\begin{array}{l}\mathbf{M} \\
\mathbf{M}\end{array}$ & $\begin{array}{l}\text { I948 } \\
\text { I } 950\end{array}$ & $\begin{array}{l}1955 \\
1957 \\
1972\end{array}$ & $\begin{array}{l}0.26 \\
0.22 \\
0.54\end{array}$ & $\begin{array}{l}0.18 \\
0.18 \\
0.20\end{array}$ & $\begin{array}{l}+ \\
+ \\
+\end{array}$ \\
\hline IV.8 & $\mathbf{F}$ & 1972 & 1972 & 0.17 & 0.12 & + \\
\hline V.2 & $\mathrm{F}$ & 1970 & 1972 & 0.16 & 0.16 & + \\
\hline
\end{tabular}

* The pulmonary artery was not reached by the catheter during the study.

\section{Case IV.8}

The daughter of III.6, and the cousin of the proband's father. She was delivered by vacuum extraction I4 days after term (her mother's first pregnancy). Weight and length at birth were $2650 \mathrm{~g}$ and $49 \mathrm{~cm}$, respectively. Shortly after birth she developed tachypnoea. Electrocardiogram showed a prolonged PR interval (Table) and $x$-ray revealed an enlarged heart with dilated lung vessels. A catheter study demonstrated an atrial septal defect (Table).

\section{Case II.3}

The proband's great-grandfather. He died suddenly on his way home from work at the age of almost 60 years. He had been examined twice as an outpatient in the local hospital 5 and 3 years earlier with the diagnoses: (1958) 'combined aortic stenosis and insufficiency' and (I960) 'mitral heart'. This was based on the findings of both systolic and diastolic murmurs, a pronounced enlargement of the heart, and atrial fibrillation. An electrocardiogram showed a complete right bundle-branch block. In restrospect it seems likely that this patient, too, had a secundum type atrial septal defect.

\section{Cases III.4, III.5, and III.7}

Sibs of the proband's grandfather. These 3 members of the family have not been seen and the description was given by their mother. The family at that time lived far away and the hospital records of the youngest of these patients were burnt. The first patient failed to thrive from shortly after birth. She had slight cyanosis and died in 1942 at 6 months of age. Her brother was well at birth, but later he, too, failed to thrive. At 4 months of age he contracted pneumonia, from which he died a month later. The youngest of these 3 also looked well at birth, but from I or 2 months of age she had dyspnoea and after her sixth month she had several upper and lower respiratory infections. In her second year congenital heart disease was mentioned. Oedema in the legs and a pronounced heart enlargement were discovered at the local hospital 2 weeks before her death at 20 months of age.

\section{Cases IV.4 and IV.6}

Spontaneous abortions in the 7 th and 3 rd months, respectively.

\section{Remaining family}

Examinations for possible congenital heart disease have been negative in the rest of the family members in the generations III, IV, and V.

Except for Case II.5 all members of generation II have been examined by auscultation and electrocardiogram. Atrial fibrillation was found in 4 of them (II.2, II.4, II.6, II.7) in addition to that of the proband's great-grandfather. In none of them is there any evidence for an atrial septal defect. Case II.7 was, however, operated on for mitral stenosis in 1953 and 1972 . Neither during the operations, nor in the catheter study before the last operation, was any atrial septal defect detected.

The information about generation $I$ is contradictory, but it seems likely that the father died at 70 and the mother at 80 years of age. There is no further information about patients with congenital heart disease in the family.

In all living subjects with atrial septal defect normal $x$-rays of the forearms have been recorded. 


\begin{tabular}{llll}
\hline $\begin{array}{l}\text { Age at time } \\
\text { of catheter } \\
\text { study }\end{array}$ & \multicolumn{2}{|c|}{ Pressures $(\mathrm{mmHg})$} & Flow \\
\cline { 2 - 3 } & $\begin{array}{l}\text { Right } \\
\text { ventricle }\end{array}$ & $\begin{array}{l}\text { Pulmonary } \\
\text { artery } \\
(\text { mean })\end{array}$ & $\dot{\mathrm{Q}}_{\mathrm{p}}$ \\
\hline
\end{tabular}

No study

\begin{tabular}{|c|c|c|}
\hline $46 \mathrm{yr}$ & 55 & $\underline{53}(25)$ \\
\hline & $\overline{0-8}$ & $\overline{14}$ \\
\hline $7 \mathrm{yr}$ & $\underline{51}$ & $\star$ \\
\hline & $\overline{+2}$ & \\
\hline No stuc & & \\
\hline $22 \mathrm{yr}$ & 25 & 20 (13) \\
\hline & 0 & 7 \\
\hline 3 wk & $40-48$ & $\star$ \\
\hline & 2 & \\
\hline $\mathrm{I} \frac{1}{2} \mathrm{yr}$ & 26.5 & 22.5 (13) \\
\hline & $I-6$ & 9 \\
\hline
\end{tabular}

\section{Discussion}

The reported family seems to fill the criteria for autosomal dominant inheritance with complete penetrance. There is an almost equal distribution between children with and without atrial septal defect in the different sibships, and the affected members always have one parent with an atrial septal defect. There is also an equal distribution between the sexes among the 6 assured cases, and also among the 4 deceased members of the family, who probably have had atrial septal defect.

In the family's two branches (III.2 and III.6) it seems likely that the same determinant factor is at play. However, since these two family branches have different mothers, the postulated dominant gene must have come from the common father, thus giving further evidence for the dominant mode of inheritance.

The fact that only case 3 in generation II is affected may be explained by a spontaneous mutation in this patient.

As in the reports of Howitt (196I), Weil and Allenstein (196I), Kahler et al. (1966), Amarashingham and Fleming (1967), and Bizarro et al. (1970), all our patients had a prolonged PR interval, except for V.2 where the atrioventricular conduction time was at the upper normal limit for age. The importance of this observation is uncertain, but there is a pronounced tendency towards developing atrial fibrillation or flutter, which already affects 3 of our patients. The atrioventricular conduction time in
IV.3 has increased during the 15 years since 1957. Bizarro et al. (1970) and Kahler et al. (1966) suggest that a prolonged PR interval could be useful in distinguishing between atrial septal defect of dominant and polygenic nature, respectively. However, in the family of Zetterqvist et al. (197I) the PR interval was moderately prolonged only in one patient.

The suspicion that this syndrome might be an abortive form of the Holt-Oram syndrome could not be substantiated through $x$-rays of both hands, forearms, and elbows of all living members of the family having an atrial septal defect, and this agrees with the observations of Kahler et al. (1966).

Considering the early deaths of IV.I and of the 3 children in generation III it seems that this type of atrial septal defect has not such a benign natural history as that usually found in atrial septal defect. The reports of Campbell and Polani (196r) and Zetterqvist et al. (197I) also each listed one early death, the former at 6 months of age, the latter caused by heart failure in the fourth month. This further substantiates our suspicion.

\section{Conclusion}

The occurrence of atrial septal defect is fairly common, though there are few reports of kindreds with an apparently dominant mode of inheritance. Most cases are, therefore, assumed to be caused by multifactorial or polygenic mechanisms. It seems very likely, however, that in this and some other kindreds a major, dominant gene, not sex-linked, is operating, which, with a high degree of penetrance and a little degree of variation in expressivity, causes atrial septal defect, in most kindreds with, and in others without, a prolonged atrioventricular conduction time.

\section{References}

Amarashingham, R., and Fleming, H. A. (1967). Congenital heart disease with arrhythmia in a family. British Heart fournal, 29, 78.

Bizarro, R. O., Callahan, J. A., Feldt, R. H., Kurland, L. T., Gordon, H., and Brandenburg, R. O. (1970). Familial atrial septal defect with prolonged atrioventricular conduction. A syndrome showing the autosomal dominant pattern of inheritance. Circulation, 41, 677.

Campbell, M. (1949). Genetic and environmental factors in congenital heart disease. Quarterly fournal of Medicine, 18, 379.

Campbell, M., and Polani, P. E. (1961). Factors in the aetiology of atrial septal defect. British Heart fournal, 23, 477.

Carleton, R. A., Abelmann, W. H., and Hancock, E. W. (1958). Familial occurrence of congenital heart disease. New England fournal of Medicine, 259, 1237.

Davidsen, H. G. (1958). Atrial septal defect in a mother and her children. Acta Medica Scandinavica, 160, 447. 
Ehlers, K. H., and Engle, M. A. (1966). Familial congenital heart disease. I. Genetic and environmental factors. Circulation, 34, 503.

Emanuel, R. (1970). Genetics and congenital heart disease. British Heart fournal, 32, 281.

Holt, M., and Oram, S. (1960). Familial heart disease with skeletal malformations. British Heart fournal, 22, 236.

Howitt, G. (196I). Atrial septal defect in three generations. British Heart fournal, 23, 494.

Kahler, R. L., Braunwald, E., Plauth, W. H., Jr., and Morrow, A. G. (1966). Familial congenital heart disease. American fournal of Medicine, 40, 384 .

Nora, J. J., McNamara, D. G., and Fraser, F. C. (1967). Hereditary factors in atrial septal defect. Circulation, 35, 448.
Weil, M. H., and Allenstein, B. J. (196I). A report of congenital heart disease in five members of one family. New England Fournal of Medicine, 265, 661.

Zetterqvist, P., Turesson, I., Johansson, B. W., Laurell, S., and Ohlsson, N-M. (1971). Dominant mode of inheritance in atrial septal defect. Clinical Genetics, 2, 78.

Zuckerman, H. S., Zuckerman, G. H., Mammen, R. E., and Wassermil, M. (1962). Atrial septal defect. Familial occurrence in four generations of one family. American fournal of Cardiology, 9, 515.

Requests for reprints to Dr. Per G. Björnstad, Department of Paediatric Cardiology, Paediatric Clinic, University of Göttingen, D-34 Göttingen, Humboldtallee 38, West Germany. 